\title{
HVMANITAS
}

\section{Em Knossos, de Hélia Correia: notas de leitura: I}

Autor(es): Hörster, Maria António; Siva, Maria de Fátima

Publicado por: Imprensa da Universidade de Coimbra

URL

persistente:

URI:http://hdl.handle.net/10316.2/35058

DOI:

DOI:http://dx.doi.org/10.14195/2183-1718_66_22

Accessed : $\quad$ 26-Apr-2023 12:05:59

A navegação consulta e descarregamento dos títulos inseridos nas Bibliotecas Digitais UC Digitalis, UC Pombalina e UC Impactum, pressupõem a aceitação plena e sem reservas dos Termos e Condições de Uso destas Bibliotecas Digitais, disponíveis em https://digitalis.uc.pt/pt-pt/termos.

Conforme exposto nos referidos Termos e Condições de Uso, o descarregamento de títulos de acesso restrito requer uma licença válida de autorização devendo o utilizador aceder ao(s) documento(s) a partir de um endereço de IP da instituição detentora da supramencionada licença.

Ao utilizador é apenas permitido o descarregamento para uso pessoal, pelo que o emprego do(s) título(s) descarregado(s) para outro fim, designadamente comercial, carece de autorização do respetivo autor ou editor da obra.

Na medida em que todas as obras da UC Digitalis se encontram protegidas pelo Código do Direito de Autor e Direitos Conexos e demais legislação aplicável, toda a cópia, parcial ou total, deste documento, nos casos em que é legalmente admitida, deverá conter ou fazer-se acompanhar por este aviso. 
humanitas

Vol. LXVI

2014

IMPRENSA DA UNIVERSIDADE DE COIMBRA

COIMBRA UNIVERSITY PRESS 


\title{
Em Knossos, de Hélia Correia. Notas de leitura - I
}

\author{
Hélia Correia, At Knossos. Some notes - I
}

\author{
Maria António Hörster e Maria de Fátima Silva \\ Centro de Estudos Clássicos e Humanísticos da Universidade de Coimbra \\ mahorster@sapo.pt e fanp13@gmail.com
}

...porque nunca consigo abrir os meus livros gregos e fechá-los depressa - têm íman nas páginas!

Hélia Correia (2007)

\section{Resumo}

Como preâmbulo à sua pequena obra Apodera-te de mim, Hélia Correia produz uma reflexão inspirada em Knossos, como ponto de partida para a evolução cultural e social que o teatro e a oposição de géneros representam. A partir de uma distância que a própria cosmogonia determina, a cultura promove, com base na compreensão e no amor, o indispensável encontro.

Palavras chave: Grécia, teatro, papéis de género, natureza, cultura.

\begin{abstract}
As a preface to her short text Apodera-te de mim ("Take me"), Hélia Correia produces a reflection inspired by Knossos as a starting point to the cultural and social evolution, established by theatre and the opposition of genders. From a distant moment of cosmogony, culture promotes, through comprehension and love, the inevitable coming together.
\end{abstract}

Keywords: Greece, theatre, gender roles, nature, culture.

Para celebração do aniversário de Jaime Rocha, Hélia Correia promoveu um pequeno volume intitulado Apodera-te de mim (2002), que quis 
partilhar com um círculo estreito de amigos. Este opúsculo é composto por quatro textos, que desenvolvem uma reflexão coerente sobre o processo civilizacional, em particular o relacionamento de géneros em sociedade, à luz de critérios helénicos: Em Knossos, A de Cólquida, Penthesiléa e Tene me. O primeiro, Em Knossos, pode ler-se como um proémio, em que se enunciam as grandes ideias sobre que assenta esta criação: o teatro, na sua relação com a vida, e o processo de afirmação feminina enquanto ser cultural. A de Cólquida e Penthesiléa constituem reescritas de paradigmas míticos, que concretizam a mesma problemática. Finalmente, Tene me, que inspira o título da colectânea, apresenta-se como uma espécie de relato de vida com os seus variados e controversos matizes.

Vamos, neste momento, limitar a nossa reflexão ao texto de abertura.

\section{Ao princípio ... era o teatro}

\section{Em Knossos I}

Caia a mulher de encontro à terra, diz o coro.

Não sabe que, mais tarde, aceitará um lugar sobre o palco . $O$ velho mundo será então motivo nas tragédias e dele se tirará uma lição que, na verdade, não se encontra aqui.

Pode dizer-se que vos falo de um teatro, pois é um sítio feito para que os olhos testemunhem a morte e comuniquem a todo o corpo o seu comprazimento.

Os pequenos desníveis da encosta onde tremem, de pé, os assistentes, virão mais tarde a elevar-se, de maneira que as suas pedras servirão de assento.

Esse conforto moralizará o sentimento dos espectadores.

O sangue será tido por obsceno e o que é visível não o incluirá.

Se eu predissesse que haverá um tempo em que o golpe será sem consequências e a imolada tornará a levantar-se, porque a realidade passará o seu terror para os criadores do texto, ninguém se deteria para me ouvir.

$E$, no entanto, a fala das mulheres, soprada pelas serpentes subterrâneas, ainda assusta e é levada em conta.

A primeira questão que se coloca é a da entidade enunciadora do discurso e do estatuto que se arroga. A voz que nos chega é a de uma 
instância 'filosófica', capaz de penetrar na essencialidade das coisas e dos processos, a qual, a partir do veredicto pronunciado por um coro, especula sobre o sentido profundo da vida humana e a sua re-presentação (mimesis) no teatro. Ao coro, como é usual na tragédia, atribui-se a autoridade de quem detém uma visão universal da ordem cósmica; e aqui essa voz plural lança um imperativo, que remete a mulher para a sua condição elementar de ser ligado à terra e, com isso, ao que de mais genuíno existe na natureza ${ }^{1}$. A esta voz socialmente consagrada vai de imediato contrapor-se a sabedoria oracular do eu textual, que nos faz lembrar o processo de inspiração délfico, em que os ditames do deus são filtrados e transpostos para palavras pela figura feminina da pitonisa.

Subjacente ao texto está o confronto civilizacional entre Creta e a Ática: "Knossos" remete para a cultura minóica, núcleo embrionário da cultura helénica, posta em contraposição com o estádio clássico que Atenas virá, milénios mais tarde, a centralizar. No entanto, apesar da distância temporal e espacial, o diálogo entre estes dois pólos decorre sem ruptura ${ }^{2}$.

Metonimicamente, é o teatro que delineia o perfil cultural de Atenas. Desconhecido da civilização cretense que Knossos simboliza, o teatro surge na Ática como um fenómeno de improvisação ${ }^{3}$, global na sua mensagem e no alvo social a atingir. Se a etimologia de 'teatro' - "lugar onde se observa" - parece valorizar a dimensão essencialmente visual do espectáculo,

1 Hélia Correia retorna aqui, ainda que de forma apenas sugestiva, a uma prática que segue em duas das suas peças inspiradas em mitos clássicos, Perdição. Exercício sobre Antígona (1 ${ }^{a}$ ed. 1991. Lisboa. Publicações D. Quixote; reimpr. 2006. Lisboa. Relógio d'Água: 17-22) e Desmesura. Exercício com Medeia (2006. Lisboa. Relógio d’Água: 13-15). O coro tem, nestes textos dramáticos, uma intervenção inicial para sintetizar e comentar os fios condutores de toda a intriga. Em ambos os casos, por se tratar de temáticas focadas em volta da problemática feminina, as intervenções corais abordam também a definição da condição da mulher e o conflito de géneros. Além do tema, como veremos adiante, também os efeitos literários e as imagens poéticas usadas nestes dois cantos do coro estabelecem relações de intertextualidade com Em Knossos.

2 O estudo do processo de evolução civilizacional da cultura minóica para a micénica e toda a polémica que envolve, acrescido de informação bibliográfica, é sintetizado por M. H. Rocha Pereira (102006), Estudos de História da Cultura Clássica I. Cultura Grega. Lisboa. Gulbenkian: 31-46.

3 Aristóteles, Poética 1448b 20-23: "Estando, pois, de acordo com a nossa natureza a imitação, a harmonia e o ritmo (...), desde tempos remotos, aqueles que tinham já propensão para estas coisas, desenvolvendo pouco a pouco essa aptidão, criaram a poesia a partir de improvisos". Tradução de A. M. Valente (2004), Aristóteles. Poética, Lisboa: Gulbenkian. 
Hélia reconhece essa componente primordial, a que acrescenta a vocação para o desencadear de emoções. Nesta fase inicial, a tragédia toma como seu motivo situações radicais, de alcance universal, oferecidas a nu com toda a sua crueza: "para que os olhos testemunhem a morte". Apesar do espaço precário, estas situações detêm uma força capaz de mobilizar as emoções dos 'assistentes', ainda não tecnicamente "espectadores", que, "de pé", "tremem", acusando, com esta reacção física, o impacto do que os olhos testemunham ${ }^{4}$.

Após esta primeira etapa de improvisação, o fenómeno teatral, acompanhando a própria evolução da polis, sofre uma verdadeira institucionalização. A precariedade inicial - "pequenos desníveis da encosta" - dá lugar a espaços construídos, de que as "pedras" são um alicerce de estabilidade e comodidade imediatas, sinalizando ainda a fortuna duradoura da instituição teatral. De par com a comodidade física do espectador, também o próprio espectáculo se moraliza, erradicando da cena a crueza sanguinária de uma acção, que não perde, no entanto, a sua agressividade inicial.

Denunciando o conhecimento da evolução do género trágico, o eu textual aponta para o último estádio protagonizado por criadores como Eurípides. Se, em Ésquilo, por exemplo, a imolação de Ifigénia, no Agamémnon, é irremediavelmente concretizada, Eurípides, na última das tragédias que conservamos, Ifigénia em Áulide, contorna o definitivo desta morte com o milagre que, por intervenção divina, arrebata a vítima do altar do sacrifício, para a depor a salvamento em exóticas paragens. Episódios como este exemplificam a penetração na tragédia de novos condimentos dramáticos e estéticos, frequentemente de sabor romanesco, que fazem sentir o seu efeito não apenas à superfície, mas subvertem no essencial o sentido de trágico. Com eles, a violência da realidade é suavizada, não apenas na imagem, mas na própria concepção, e poupadas tensões emotivas no espectador. Este é, em boa parte, o termo da trajectória seguida pela tragédia no final do séc. V a. C.

4 Será oportuno recordar a essência de 'mito', isto é, das velhas histórias que a tragédia usou como sua fonte inspiradora, nas palavras esclarecidas de W. Burkert (1986, Mito e Mitologia, trad. portuguesa de M. H. Rocha Pereira, Coimbra. Faculdade de Letras: 12): "A maior parte das sequências narrativas são, no fundo, tão simples como fundamentais, actantes 'bióticos' (...), que estavam desde há muito delineados em modelos de comportamento, na procura da alimentação, luta, sexualidade. Mas há uma particularidade que deve caracterizá-los como 'estranhos', para entrarem na tradição narrativa, um elemento excepcionalmente reforçado ou uma espécie de congruência cristalina ou paradoxal". 
Num curioso apontamento, que implicará certamente a experiência da própria autora, o terror de que o espectador era o destinatário passou a ser assumido pelos "criadores de texto". São estes que arcam consigo a brutalidade genuína da acção e a filtram, por recursos de fantasia, para a transmitirem de forma suavizada aos receptores ${ }^{5}$.

Não obstante este processo de aculturação impresso, pela mão dos homens, sobre a tragédia, a voz das mulheres, como se lê no juízo com que termina este segmento do texto, conserva a força primordial que lhes advém da sua ligação profunda à natureza. Hoje, como na velha Knossos, a palavra da mulher, "soprada pelas serpentes subterrâneas", veicula as mesmas verdades essenciais e, por isso, desencadeia o terror e se lhe reconhece autoridade.

Anunciado na frase de abertura, o tema da mulher - "Caia a mulher de encontro à terra, diz o coro" -, então anulada enquanto ser cultural, conhece neste remate um clímax que anuncia o movimento geral de Em Knossos.

\section{Mulher - condenada e rebelde}

\section{Em Knossos II}

Caia a mulher à terra, diz o coro. Que ela retorne à posição deitada da qual nunca haveria de sair.

Que ela rasteje como um mármore animado, caos de elementos, anterior aos bichos.

5 Julgamos pressentir, por sob o padrão discursivo de "Se eu predissesse que haverá um tempo em que [....] ninguém se deteria para me ouvir. E, no entanto, a fala [...]" a pergunta angustiada com que abre o ciclo poético As elegias de Duíno, de Rainer Maria Rilke: "Quem, se eu gritasse, me ouviria dentre as ordens/ dos anjos? E mesmo que um me apertasse [...]". (Rilke / Paulo Quintela, 1969: 35). Acerca da energia contagiante desse incipit, que repercutiu em autores tão distintos como Armando Cortes-Rodrigues, Yvette Centeno, David Mourão Ferreira, Carlos de Oliveira, Manuel Alegre, entre outros, vd. Hörster, 2000.

Que Hélia Correia é leitora privilegiada de Rilke testemunham-no as palavras que proferiu aquando do $14 .^{\circ}$ Encontro de Estudos Portugueses, que teve lugar na Universidade de Aveiro, nos dias 15 e 16 de Novembro de 2007: "Há frases absolutamente poderosas, tão densas como um buraco negro e potencialmente tão destruidoras. Por exemplo, Rilke, num livro que é um dos meus preferidos, Os cadernos de Malte Laurids Brigge, faz-nos entrar na cena seguinte: o pai do narrador morrera de uma morte rápida e, temendo ser enterrado vivo, tinha deixado instruções para que o médico lhe espetasse uma faca no coração de forma a não restarem dúvidas quanto à sua morte. Nessa cena magnífica, o cirurgião cumpre a vontade do senhor e espeta-lhe o bisturi no coração.” Correia, 2007: 16-17. 
Vede o seu cabelo claro, um pó de trigo, um turbilhão de areia, pequena coisa concebida para arder.

Jaz, espreitando pelos seus buracos, atravessada como uma armadilha no trilho dos viajantes. Detestável, solitária entre os seres, ainda quando encostam as cabeças e se ajudam umas às outras, no momento de parir.

Crescem, teimosas como vegetais, ligeiramente trémulas do esforço.

Se a brisa as toca, dobram a cintura e a isso chamam dança e não defesa, como chamam amor à momentânea inflamação do sexo.

Se, no primeiro tempo, acompanhámos a evolução cultural expressa no trágico, somos agora confrontados com uma eloquente imagem da mulher enquanto ser socialmente condenado. Começa por retomar-se o veredicto inicial do coro, agora alargado e transformado em verdadeira condenação, que se pretenderia definitiva. Num retorno ao momento inicial da cosmogonia, à mulher é atribuída a condição de magma informe, caótico, anterior à própria criação animal $^{6}$. Se Aristóteles considera, como diferença relevante entre a espécie humana e a animal, a posição erecta ${ }^{7}$, na voz masculina deste coro a mulher é remetida para "a posição deitada" e assim, ao mesmo tempo, despromovida da elevação humana e confinada a uma função sexual.

Num efeito de zoom, a voz textual atrai o nosso olhar para uma imagem da mulher enquanto objecto de desejo. Como atributo de feminilidade e sedução sobressai o cabelo ${ }^{8}$, associado a imagens de fragilidade, inconsistência e caos,

6 Na Teogonia de Hesíodo (123-124), em que está em causa o processo de formação dos elementos naturais, os primeiros movimentos cosmogónicos, a partir de um Caos inicial, dão prioridade ao elemento masculino: primeiro constitui-se o Érebo e só depois a negra Noite e, por sua vez, da Noite, surge em primeiro lugar o Éter e só depois o Dia brilhante (em grego feminino). No livro do Génesis, a mulher, tal como o homem, é criada por Deus no sexto dia, ainda que num segundo momento.

7 História dos animais 494a: "No ser humano, mais do que nos outros animais, a distinção entre parte superior e inferior faz-se segundo as próprias posições naturais. Por outras palavras, as partes alta e baixa do homem são definidas de acordo com as partes alta e baixa do universo [...]. Assim, a cabeça, em todos os animais, está acima do resto do corpo. Mas só o homem [...], completado o seu desenvolvimento, a tem em cima em relação ao universo".

8 O cabelo tornou-se, em Hélia Correia, uma insígnia distintiva da mulher. Assim, na peça Rancor. Exercício sobre Helena (2000. Lisboa. Relógio d'Água: 43-46), a rainha de 
como são o "pó”, o "turbilhão" e as matérias para arder. O único lugar que a sociedade civilizada lhe reconhece é o da servidão sexual e o da procriação 9 . Numa certa concepção misógina que aflora na cultura grega, a maternidade, como função exclusiva das mulheres, é repudiada de um mundo ideal em que a geração fosse assegurada por outro meio, dispensando o feminino ${ }^{10}$. Nas funções que a natureza lhes atribui, as mulheres, detestadas e arredadas da cidade, formam como que uma tribo à parte, demonstrando, mesmo nessas circunstâncias adversas, a capacidade de desenvolver sentimentos de solidariedade.

A mesma natureza que as condenou a esta subserviência deu-lhes, porém, armas para resistirem. Num gesto de rebeldia, elas elevam-se acima da posição rastejante e, como vegetais, conquistam uma verticalidade flexível. Vão ainda além da mera resistência, sendo capazes de extrair desse esforço valores estéticos. É assim que, na sua obediência aos impulsos da brisa, se inclinam, criando a dança. Ao mesmo tempo, assumem o estatuto de criadoras de linguagem ${ }^{11}$, condicionando a realidade em função dos nomes que dão

Esparta assume a personalidade que lhe cabe em cada uma das duas versões da sua história - a troiana e a egípcia -, conforme a cabeleira que usa. Em Desmesura. Exercício com Medeia, as personagens femininas ganham nome a partir da cor dos cabelos, Melana "a de cabelo negro", ou Éritra, "a de cabelo ruivo". Para esta preferência, Hélia encontra modelos na Antiguidade; desde logo em Homero, que já se refere a "Helena de bela cabeleira" (Ilíada 3. 329) e, com o epíteto de eúkomos, a deusas e mortais (e. g., Ilíada 1. 36, 2. 689, Odisseia 12. 389). Mais tarde Eurípides, fiel ao modelo épico, mantém a cabeleira como insígnia de uma Helena coquette que, depois de regressada a Esparta, no final da guerra, quando confrontada com a desgraça e a morte que se prolongam dentro das casas gregas no regresso dos heróis, mantém ainda a preocupação de cortar ao de leve alguns anéis de cabelo, como oferenda à irmã falecida, Clitemnestra, mas sem lesar a sua bela cabeleira (Orestes 128-129).

9 Cf. Perdição: 17-22.

10 Cf. a rhesis misógina de Hipólito, em Eurípides, Hipólito 616-624: “Ó Zeus, porque terás tu infligido aos homens essa pecha maldita, as mulheres, porque as trouxeste tu à luz do dia? Se querias disseminar a raça humana, não seria das mulheres que se devia esperar esse papel. Contra o peso do ouro, ou do ferro, ou do bronze depositado nos templos, devia poder comprar-se a semente dos filhos, para cada um de acordo com as suas posses, de modo a manter livres delas as nossas casas."

11 Com esta imagem da mulher como instituidora de linguagem, Hélia Correia desafia a visão estabelecida no Génesis (www.bibliaonline.com.br/acf/gn/2): "Havendo, pois, o Senhor Deus formado da terra todo o animal do campo, e toda a ave dos céus, os trouxe a Adão, para este ver como lhes chamaria; e tudo o que Adão chamou a toda a alma vivente, isso foi o seu nome. E Adão pôs os nomes a todo o gado, e às aves dos céus, e a todo o animal do campo" (Génesis 2. 19-20). 
às coisas ${ }^{12}$. A brutalidade bélica e sexualizada do universo masculino cede lugar à estética e à emoção espiritualizada: à "defesa" chamam "dança" e à "inflamação do sexo", "amor"13. Não será despiciendo lembrar que Hélia Correia se dedicou à dança, encontrando-se portanto aqui convocadas as duas formas de expressão artística - literatura e dança - que a identificam.

Acompanhando a dimensão espiritual desta afirmação feminina, o texto adquire uma tonalidade manifestamente lírica, transportada por uma prosa poética de ritmo essencialmente decassilábico14: "Crescem, teimosas como vegetais, / ligeiramente trémulas do esforço. / Se a brisa as toca, dobram a cintura / e a isso chamam dança e não defesa, / como chamam amor / à momentânea inflamação do sexo."

\section{O grande amor ... não tem nome}

\section{Em Knossos III}

As mulheres refugiam-se no alto, sob as malhas de prata do olival, de onde, a seguir, se desce para o mar. Não são, por isso, menos espectadoras, com os olhos presos no altar da arena, $e$

12 É um elemento comum no pensamento estético de Hélia Correia a noção de orthoepeia, um conceito de 'rigor da palavra usada', proclamado pela intelectualidade sofística da Atenas do séc. V a. C. Trata-se de um conceito especificamente ligado ao nome de Protágoras e que teve em Pródico, com o seu princípio da onomáton orthótes ('o rigor dos nomes'), um continuador (cf. Platão, Eutidemo 277e, Fedro 267e, Protágoras 339a', Crátilo 384b, 391 a-c; Aristóteles, Retórica 1407b, Poética 1456b 15-18). Sobre este assunto, vide R. Pfeiffer (1968), History of Classical Scholarship from the beginnings to the end of the Hellenistic Age. I. Oxford, Clarendon Press: 32-56; P. B. R. Forbes (1933), "Greek pioneers in Philology and Grammar", Classical Review 47: 105-112. Um bom exemplo desta mesma preocupação em Hélia Correia se encontra em Desmesura: 28, quando estão em discussão os sentimentos que poderão ter levado Medeia ao filicídio: "Abar - A pobre! Causaria compaixão se se chamasse angústia aquilo que sente. Mas em nenhuma língua eu sei dar nome à coisa sem medida que a possui. - Melana - Tu não conheces a palavra, Abar? Nunca a pronunciaste? É o ciúme. - Abar - Isto é mais que ciúme. É desvario".

13 Cf. Hélia Correia, Desmesura: 32: "Dá-se o nome de amor a muita coisa. Até a uma força que destrói”.

14 Esta predilecção de Hélia Correia pelo ritmo decassilábico manifesta-se igualmente nas suas obras em prosa, mesmo em passos de temática repelente; cf. Lillias Fraser (reimpr. 2003), Lisboa. Público: 71: “ 'A terceira visão', pensava, ouvindo / as vozes das mulheres da sua infância, / quando se recolhiam à passagem / de certa velha, ou de uma ruiva sem pestanas, / para que elas as não vissem rebentadas, / com os vermes saindo do nariz". 
não se sabe se o horror lhes toca os nervos do prazer.

Pois a verdade é que dançam também. Entre os seus pés e os pés dos homens no anfiteatro passa um fio e um calor que os une mais do que os uniu o leito conjugal.

É necessário que a mulher condenada se debata, que o sangue escorra dela devagar, que o seu executor receba e entenda a sua exalação de moribunda, para que o encontro seja completado. Pois Eros, o risonho, não nasceu, e o grande amor, que é este, não tem nome porque não tem, sequer, repetição.

Os que virão, irão pensar depois que assim se paga algum tributo aos deuses.

Irão pensar religiosamente sobre a cerimónia puramente humana.

Deuses, se aqui passarem, pousarão discretamente os olhos noutro lado, sem que o assunto os tente.

Nem confessam que este terreno instante lhes escapa.

Nele não encontram nem arrogância, fácil de castigar, nem a desordem, fácil de converter.

Se alguma vez a criatura humana se bastou, foi nesta apoteose de caçada.

Num efeito de síntese, este terceiro momento retoma os temas do teatro, como símbolo da polis, e o da exclusão da mulher, encontrando para as fracturas antes enunciadas entre a physis e o nomos um patamar de conciliação ${ }^{15}$.

Regressa o tema do teatro enquanto edifício e enquanto lugar de representação de emoções. Enquanto edifício, o espaço sinaliza a distância cívica dos géneros: às mulheres acolhe-as “o alto", lugar de exclusão por um lado, mas privilegiado pela proximidade com os deuses e pela perspectiva abrangente que proporciona. Protegidas pela sombra das oliveiras, elas são

15 A dicotomia physis / nomos teve origem entre os sofistas e veio colocar, numa sociedade que progredia no sentido da democratização, o problema do relacionamento entre a individualidade como um oposto àquilo que se poderá designar por 'etiqueta social'. Cf. E. Dupréel (1948), Les Sophistes, Neuchâtel, Éditions du Griffon: 22-30; G. B. Kerferd (1981), The Sophistic Movement. Cambridge, University Press: cap. X; W. K. Guthrie (1971), The Sophists. Cambridge, University Press: cap. IV. 
por isso dilectas da natureza e da deusa Atena, protectora de uma Acrópole que ela dotou com a oferta daquela árvore, emblema de perenidade. Mesmo se discriminadas espacialmente, as mulheres conquistam a posição de 'espectadoras'; este termo, além de as identificar como participantes do ritual, exprime também a própria evolução a que o fenómeno teatral foi sujeito: de improviso, ei-lo integrado na vida da comunidade e entendido como um processo religioso e técnico. "Com os olhos presos no altar da arena", as mulheres mobilizam-se para captar a emoção do espectáculo e o espírito sacro que perpassa todo o recinto.

A participação no ritual assume um envolvimento crescente; de espectadoras, elas passam a integrar em pleno, na medida em que "também" dançam, a magia da celebração. Como factor referencial, a dança, a que o próprio teatro deve a sua origem, anula o lapso temporal e traz ao convívio dos cidadãos toda a tradição que lhe está subjacente. Entrar na dança é, além disso, participar numa coreografia, mobilizadora de elementos masculinos e femininos, em que todos ocupam uma posição simétrica e cumprem um ritmo equivalente. A distância entre os sexos é assim superada, numa cadência de passos que é mais integradora do que a própria união sexual. Desta maneira, a relação homem / mulher estabelece-se mais intimamente pelo espírito e pela compreensão da vida patente no teatro.

Se nos dois primeiros parágrafos a entidade responsável pelo discurso assume um tom narrativo de quem constata a evolução de práticas sociais, no terceiro adquire um tom doutrinário e comentador. É chegado o momento, depois de avaliados as condicionantes e os papéis de cada género nas suas diferenças, de promover entre eles a desejável harmonia. Na perspectiva dessa voz textual, o primeiro passo a dar no sentido dessa consonância cabe à mulher, que deve rebelar-se e controlar as tendências biológicas da sua physis em favor da valorização da inteligência e da sensibilidade. Assim levará o seu parceiro masculino a entendê-la como um ser ao seu próprio nível, enterrando em definitivo a imagem de uma criatura menor e rastejante.

É neste plano que se dá o grande encontro, para o qual não há ainda um nome. Para a paixão a cultura grega usa o nome de Eros, para que Hélia Correia encontra, numa caricatura do mito, o epíteto de "risonho", aquele que simboliza um sentimento ligeiro, leviano e de uma alegria não justificada. Está ainda por encontrar o nome para esta outra expressão do amor, que, por tão única, não pode ter designativo convencionalmente consagrado.

Esta harmonia, construída afinal pela vontade humana, poderá levar os vindouros a procurar uma explicação mais profunda, que não dispense 
a interferência da divindade. Mas Hélia Correia concebe uma nova cosmogonia: centrada no ser humano, ela remete os deuses para o espaço da dúvida ou, quando muito, para uma marginalidade incapaz de compreender esta sentimentalidade essencial e superior que une homem e mulher. Não se aplicam neste caso as regras com que os deuses habitualmente gerem a ordem universal; não há aqui arrogância (hybris) suscitadora de castigo, nem desordem (adikía) a necessitar de correcção. Há apenas que reconhecer que o ser humano atingiu aqui um momento de perfeição e de plenitude que escapa aos deuses e parece dispensá-los.

No remate do texto apresenta-se-nos uma imagem perturbadora: a de uma apoteose, que é construída, paradoxalmente, sobre o paradigma fundamental da caçada. Mantém-se, pois, um padrão de vida como perseguição entre o caçador e a sua vítima, mas redimido pelo encontro amoroso entre géneros para que se não encontrou ainda o nome exacto.

\section{Bibliografia}

-Perdição. Exercício sobre Antígona. $1^{\text {a }}$ ed. 1991. Lisboa. Publicações D. Quixote; reimpr. 2006. Lisboa. Relógio d'Água.

-Rancor. Exercício sobre Helena. 2000. Lisboa. Relógio d'Água.

-Apodera-te de mim. 2002. Lisboa. Black Sun.

-Lillias Fraser. reimpr. 2003. Lisboa. Público.

-Desmesura. Exercício com Medeia. 2006. Lisboa. Relógio d’Água.

-"Dois ofícios chamados literatura" (2007), in A. M. Ferreira / M. E. Pereira (coord.), Ofícios do livro, Universidade de Aveiro: 9-18.

-W. Burkert (1986, Mito e Mitologia, trad. portuguesa de M. H. Rocha Pereira, Coimbra. Faculdade de Letras.

-E. Dupréel (1948), Les Sophistes, Neuchâtel, Éditions du Griffon.

-P. B. R. Forbes (1933), “Greek pioneers in Philology and Grammar”, Classical Review 47: 105-112.

-W. K. Guthrie (1971), The Sophists. Cambridge, University Press.

-M. A. Hörster (2000), “Wer, wenn ich schriee, hörte mich denn aus der Engel Ordnungen?'. Alguns ecos portugueses a um verso de Rilke", in A palavra e o canto. Lisboa. Edições Colibri: 289-300.

-G. B. Kerferd (1981), The Sophistic Movement. Cambridge, University Press.

-R. Pfeiffer (1968), History of Classical Scholarship from the beginnings to the end of the Hellenistic Age. I. Oxford, Clarendon Press. 
- R. M. Rilke / Paulo Quintela (s. d. / 1969), As Elegias de Duíno e Sonetos de Orfeu. Porto. Editorial Inova.

-M. H. Rocha Pereira (102006), Estudos de História da Cultura Clássica. Cultura Grega. Lisboa. Gulbenkian.

-M. F. Silva (2006), Furor. Ensaios sobre a obra dramática de Hélia Correia. Coimbra. Imprensa da Universidade de Coimbra.

-A. M. Valente (2004), Aristóteles. Poética, Lisboa: Gulbenkian. 